\title{
Glycemic load
}

National Diabetes Information Clearinghouse (NDIC)

\section{Definitions}

Carbohydrate

Defined by National Diabetes Information Clearinghouse (NDIC)

Glycemic index

Defined by National Diabetes Information Clearinghouse (NDIC)

\section{Source}

National Diabetes Information Clearinghouse (U.S.). (2009). The diabetes dictionary. [Bethesda, Md.]: U.S. Dept. of Health and Human Services, National Institutes of Health, National Institute of Diabetes and Digestive and Kidney Diseases, National Diabetes Information Clearinghouse.

A ranking of a carbohydrate-containing food, based on the food's glycemic index and the amount of carbohydrate in a typical serving. 